\title{
Dedifferentiated Chordoma
}

National Cancer Institute

\section{Source}

National Cancer Institute. Dedifferentiated Chordoma. NCI Thesaurus. Code C48876.

A high-grade malignant bone tumor arising from the remnants of the notochord. It is characterized by a lobulated growth pattern, myxoid stroma formation, the presence of physaliphorous cells, and a sarcomatous component. 